\title{
Self-medication practice among pregnant women in Brazzaville
}

\begin{abstract}
Objectives: This study aimed to assess the magnitude of self-medication, symptoms or diseases leading to self-medication drugs used and their pharmacological classes among pregnant women.
\end{abstract}

Patients and Methods: This was a cross sectional study which was conducted using face to face interview with 350 pregnant women at government hospitals and health centres. Structured questionnaire were used. Self-medication was defined as treatment, based on symptoms, without prescription and without medical consultation during the last pregnancy. Data were analysed using Epi-info 7.2.0.1 software.

Results: Among 350 pregnant women, 41, 14\% reported self-medication. Proportion of women with self-medication schooled pregnant was $97.22 \%, 68.75 \%$ professional activity and $88.89 \%$ in couple. Mean age was $27 \pm 6.3$ years. Frequency was $97.22 \%$ among educated women, $68.75 \%$ among employed women. Self-medication was due mainly for headache $(42.22 \%)$, fever $(17.36 \%)$, malaria $(13.88 \%)$ and urinary tract infections $(8.33 \%)$. The drugs and therapeutic classes were paracetamol (analgesic) with $70 \%$ of cases, Diclofenac and ibuprofen (non-steroidal anti-inflammatory drugs) with $18.75 \%$, chloramphenicol (antibiotics) with $18.75 \%$. The major sources of drugs included, market $(55.56 \% \%)$ and pharmacies $30.88 \%$. The main reason for choice of drugs for self-medication was "safe treatment ".

Conclusion: Self-medication is common among pregnant women in Brazzaville. Our findings highlight need for prevention interventions such as sensibilisation during prenatal consultations on the risks related to the consumption of drugs without medical prescriptions and governmental actions in order to more regulate citizens access to drugs. Further studies on adverse effects are urgently needed.

Keywords: Brazzaville, Self-medication, pregnant women, antibiotics, analegic, anti-malarial, headache, pharmacies, anti-inflammatory, drugs, diclofenac, symptoms, drug interactions, antibiotics microbial, depression
Volume 2 Issue 3 - 2018

\author{
BiBintsene-Mpika G,' Mouankié JB, ${ }^{2}$ Ndziessi \\ G, ${ }^{3}$ Mozoma LO, ${ }^{4}$ Iloki LH, ${ }^{\prime}$ Abena $\mathrm{AA}^{3}$ \\ 'Department of Gynaecology \& Obstetrics, University Hospital, \\ Brazzaville, Congo \\ ${ }^{2}$ Department of biomedical Sciences, Faculty of Health Sciences, \\ Marien NGouabi University, Brazzaville, Congo \\ 3Public Health Department, Faculty of Health Sciences, Marien \\ NGouabi University, Brazzaville, Congo \\ ${ }^{4}$ Department of Physiological Sciences, University Hospital, \\ Brazzaville, Congo
}

Correspondence: BiBintsene-Mpika G, Department of Gynaecology \& Obstetrics, University Hospital, Brazzaville, P.O.Box 32, Congo, Email bmgickelle@yahoo.fr

Received: May 23, 2018 | Published: June 19, 2018

\section{Introduction}

Self-medication, described ${ }^{1,2}$ as the fact of taking medicines by oneself, based on the symptoms, without prescription medical consultation, constitutes a public health major issue. Selfmedication is associated with the risk of inappropriate drug use, which predisposes patients to drug interactions, masking symptoms of an underlying disease, and development of antibiotics microbial resistance. Self-medication practice is common worldwide ${ }^{3-8}$ Factors influencing frequency of self-medication are age, educational level, family attitudes, advertising of drug manufacturers, legislation regulating dispensing and sale of drugs, previous experiences with the symptoms or disease, significance attributed to the disease ${ }^{2-9}$ homekept prescription drugs ${ }^{10}$ and economic situation of respondents. ${ }^{1,2}$ Depression and anxiety may also be connected with self-medication. ${ }^{11}$ Self-medication is a topic of major interest in Sub-Saharan Africa where drugs purchased and used without the prescription of a physician are common. Self-medication in pregnant women is of particular interest due to teratogenic and fetotoxic effects. ${ }^{12-14}$ Self-medication among pregnant women is widely documented in sub-Saharan Africa. Available data show that self-medication is common among pregnant women. ${ }^{5-18}$ For example, in a study conducted among 145 pregnant women followed by prenatal consultations in Democratic Republic of
Congo, $75 \%$ reported use of non steriodic anti-inflammatory in selfmedication and mainly during the last two trimesters of pregnancy to treat pain from various causes..$^{15}$ In another study conducted in Ethiopia, 510 pregnant women were included and $25.1 \%$ reported self-medication. In this study, Self medication during pregnancy was significantly associated with gravid, maternal illness on the date of interview and location of health facility. ${ }^{16}$ Self-medication practice was also assessed among 617 among pregnant women in Ethiopia and prevalence was $26.6 \%$; previous pregnancy and delivery related problems were found associated with self-medication practice, ${ }^{17}$ In a study conducted in Nigeria, of the 518 pregnant women assessed, prevalence of self-medication was $72,4 \%, 41.9 \%$ for fever/pain relievers. ${ }^{6}$ Recently, self-medication was assessed in Tanzania among 372 pregnant women with a prevalence of $6.24 \%$. In this study, pregnant women with no formal education, incomplete primary education, primary education and secondary education were most likely to practice self-medication than pregnant women with college or university education. ${ }^{18}$

In Congo, Few studies have investigated self-medication practice. We found in the literature only one study conducted in Brazzaville in general population and prevalence was $68.5 \%$ (9) .No studies have investigated self-medication practice among pregnant women in 
Congo. We conducted this study among pregnant women in Brazzaville to assess prevalence of self-medication, symptoms or diseases leading to self-medication, drugs used and therapeutic classes.

\section{Methods and patients}

\section{Study design and setting}

A cross-sectional study was carried out in government Hospital and primary health centers in Brazzaville from February to July 29, 2016. Brazzaville count for four Hospitals (University Hospital, Army Hopital, Talangai and Makélékélé Districts Hospitals) and 33 primary healthcare centers. Stratified random sampling was performed to select 4 primary health centers (Marien NGouabi, Fleuve Congo, Moukondo, and Kibouendé). Three hospitals were included for study (except the military hospital for logistical considerations).

\section{Sample and data collection}

The sample size was determined by using the single population proportion formula for the prevalence $(\mathrm{N}=\mathrm{z} 2 \mathrm{pq} / \mathrm{d})$ of self-medication practice assuming 19\% prevalence during pregnancy ${ }^{5}$ at $95 \%$ confidence level, 5\% marginal error. The minimum sample size was 239 pregnant women. A total of 500 questionnaires were distributed. Final sample was 350 pregnant women. Systematic random sampling was performed to select pregnant women in study sites. Information on socio demographic characteristics (age, marital status, educational level and occupation), reproductive characteristics (experience of pregnancy, parity, previous self-medication experience), Drug used for self-medication (antibiotics, analegic, anti-malarial), Symptoms or Diseases and sources of drugs used. Participants were also asked indicate to the reasons for using the drug. A semi-structured, pretested questionnaire was designed to conducted interviews with women. Data was collected by face-to-face interview held in a private room at the study site by medicine students previously trained. Were included Women with intra-uterine pregnancy since at least 7 weeks, confirmed by obstetric scanner.

\section{Self-medication definition}

Self-medication is, in some cases, the result of therapeutic education and has favorably modified the presentation of pathological situations. This is the case with the use of inhaled corticosteroid therapy in asthma. ${ }^{13}$ This practice is not strictly speaking self-medication in the sense defined by the WHO, ${ }^{1,2}$ i.e. a situation in which no health professional participates in any stage of the therapeutic decision. In this study, Self-medication was defined as treatment, based on symptoms, without prescription and without medical consultation during the last pregnancy.

\section{Data analysis}

Pregnant women were classified into two groups according to seft-medication status: Group I (pregnant women who have reported self-medication practice) and Group 2 (pregnant women without selfmedication practice). Characteristics were compared between the two groups. Group comparisons used Pearson Chi-2 or Fisher's exact tests for frequencies and Student Test for means. The P-value of less than or equal to 0.05 was used to determine the statistical significance. Statistical analyses were performed using Epi-info version 7.2.0.1 software.

\section{Ethical considerations}

The study protocol was approved by the departmental committee of ethics in biomedical research. Each woman who agreed to participate in the study had received detailed verbal as well as written information on the aims of the study. Only women agreeing to respond to the questionnaire were included. Permission to carry out the study was obtained from the faculty of health sciences through a letter from the faculty of health sciences.

\section{Results}

\section{Characteristics of participants}

The main characteristics of the study population are presented in the Table 1. A total of 350 pregnant women participants enrolled in the 7 sites. Self-medication during pregnancy was practiced by 144 (46.24\%) pregnant women (Group I) while the remaining 205 (59\%) pregnant women were without self-medication (Group II). Mean age was $27 \pm 6.3$ years, $97.2 \%$ were literate, $88.9 \%$ in couple and $68.8 \%$ were in employment. Regarding reproductive characteristic, $85,4 \%$ have already a least 2 pregnancies in the past and $42,4 \%$ were multiparous,. At least twenty one women of 144 with selfmedication in the last pregnancy reported a history of self-medication .No significative difference was observed between women with selfmedication and women without self-medication for all characteristics analyzed except for history of self-medication $(21,5 \%$ vs. $12,5 \%$, $\mathrm{p}=0,02)$. Self-medication was $9(6,3 \%)$ during first trimester $(<15$ weeks), 59 (41\%) during second trimester (15-28 weeks) and $76(52,7 \%)$ during third trimester $(\mathrm{p}<0,001)$.

Table I Main characteristics of pregnant women involved in self-medication in Brazzaville, 2016

\begin{tabular}{|c|c|c|c|c|c|}
\hline & $\begin{array}{l}\text { Self-me } \\
(\mathbf{N}=\mid 44)\end{array}$ & cation & $\begin{array}{l}\text { Without Self- } \\
\text { medication } \\
(\mathrm{N}=205)\end{array}$ & & $\mathbf{p}$ \\
\hline Age(years \pm SD) & $67+6,3$ & & $26 a \pm 5,4$ & & 0,53 \\
\hline Education & $\mathrm{N}$ & $\%$ & $\mathrm{n}$ & $\%$ & \\
\hline $\begin{array}{l}\text { Have school } \\
\text { Attended }\end{array}$ & 140 & 97,2 & 197 & 96,1 & 0,44 \\
\hline $\begin{array}{l}\text { Not school } \\
\text { attended }\end{array}$ & 4 & 2,8 & 9 & 4,4 & \\
\hline \multicolumn{6}{|l|}{ Marital status } \\
\hline In couple & 128 & 88,9 & 184 & 89,8 & 0,89 \\
\hline Not in couple & 16 & $\mathrm{II}, \mathrm{I}$ & 22 & 10,7 & \\
\hline \multicolumn{6}{|l|}{ Occupation } \\
\hline Yes & 99 & 68,8 & 152 & 74,1 & 0,30 \\
\hline No & 45 & 31,3 & 54 & 26,3 & \\
\hline \multicolumn{6}{|c|}{ Pregnancies history } \\
\hline $\begin{array}{l}\text { At least } 2 \\
\text { pregnancies }\end{array}$ & 123 & 85,4 & 163 & 79,5 & 0,18 \\
\hline First pregnancy & 21 & 14,6 & 43 & 21,0 & \\
\hline Childbirth history & & 0,0 & & 0,0 & \\
\hline Multiparous & 61 & 42,4 & 80 & 39,0 & 0,50 \\
\hline primiparous & 83 & 57,6 & 126 & 61,5 & \\
\hline \multicolumn{6}{|c|}{ Self-medication history } \\
\hline Yes & 31 & 21,5 & 25 & 12,2 & 0,02 \\
\hline No & 113 & 78,5 & 181 & 88,3 & \\
\hline
\end{tabular}

\section{Drugs used in Self-medication}

Details of drug used for self-medication are shown in Table 2. The most commonly drug reported for self-medication were analgesics 
$(94,4 \%)$, antibiotics $(13,2 \%)$ and anti-malaria $(7,6 \%)$. Among all drugs, most commonly used was paracetamol for analgesic $(70,1 \%)$ and diclofenanc (17,4\%), cholrampphenicol for antibiotics and quinine for anti-malarial. According therapeutic classes, the most drugs used were. Sources of drugs used for self-medication were market (55\%), pharmacies (30\%), family sotorage box (8\%) and other sources $(7 \%)$ (Figure 1). Self-medication was practiced mainly for relieve headaches $(42.22 \%)$, treat fever $(17.36 \%)$, malaria $(13.88 \%)$ and urinary tract infections $(8.33 \%$ ) (Figure 2). The drugs used most often and their therapeutic classes were: paracetamol (analgesic) $70 \%$, Diclofenac/Ibuprofen (non-steroidal anti-inflammatory drugs) $24.3 \%$, chloramphenicol (antibiotics) with 6,3\% (Table 2). When considering frequency in same therapeutic class, paracetamol represented $74,3 \%$ among analgesic, quinine $81,8 \%$ among anti-malaria and chloramphenicol $47,4 \%$ among antibiotics. The major sources of drugs included, market $(55.56 \% \%)$ and pharmacies 30.88\% (Figure 1). Diseases for which self-medication has been reported in pregnant women was malaria (62\%) and urogenital infection (38\%) (Figure 3). The main reasons given to justify self-medication were a strong belief in the safety of the drug (48.6\%) and the lack of access to a health centre $(47.9 \%)$. No pregnant woman was aware of the maternal and child health risks of drugs used in self-medication.

Table 2 Names (INN) and therapeutic classes of drugs used for selfmedication among pregnant women in Brazzaville, $(\mathrm{N}=144), 2016$

\begin{tabular}{llll}
\hline & N & $\begin{array}{l}\text { \% in all self- } \\
\text { medication } \\
\text { women }\end{array}$ & $\begin{array}{l}\text { \% by therapeutic } \\
\text { class }\end{array}$ \\
\hline Name of Drug (INN) & & & \\
Analgesics & 136 & 94,4 & $(\mathrm{n}=136)$ \\
Paracetamol & 101 & 70,1 & 74,3 \\
Diclofenac & 25 & 17,4 & 18,4 \\
Ibuprofen & 10 & 6,9 & 7,4 \\
Anti-malaria & $1 \mathrm{I}$ & 7,6 & $(\mathrm{n}=1 \mathrm{I})$ \\
Quinine & 9 & 6,3 & 81,8 \\
Arthemeter/ & 2 & 1,4 & 18,2 \\
Lumefantrine & 19 & 13,2 & $(\mathrm{n}=19)$ \\
Antibiotics & 9 & 6,3 & 47,4 \\
Chloramphenicol & 2 & 1,4 & 10,5 \\
Doxycycline & 4 & 2,8 & 21,1 \\
Amoxicillin & 2 & 1,4 & 10,5 \\
Flucloxacillin & 2 & 1,4 & 10,5 \\
Cotrimoxazole & & & \\
\hline
\end{tabular}

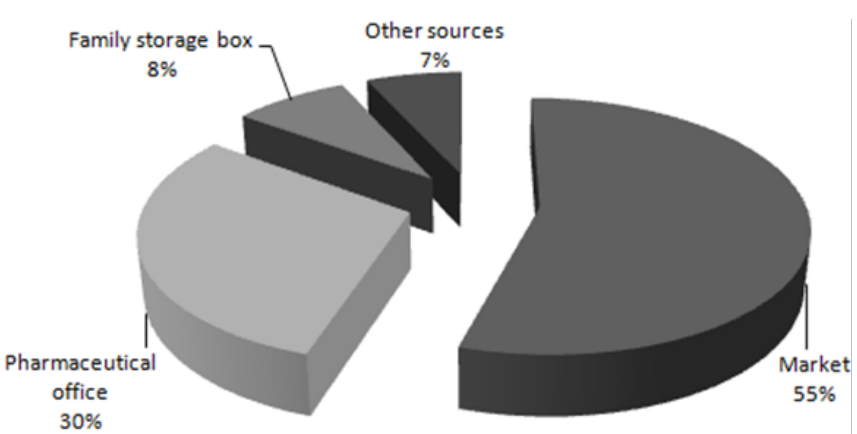

Figure I Sources of self-medication drugs for pregnant women Brazzaville, 2016.

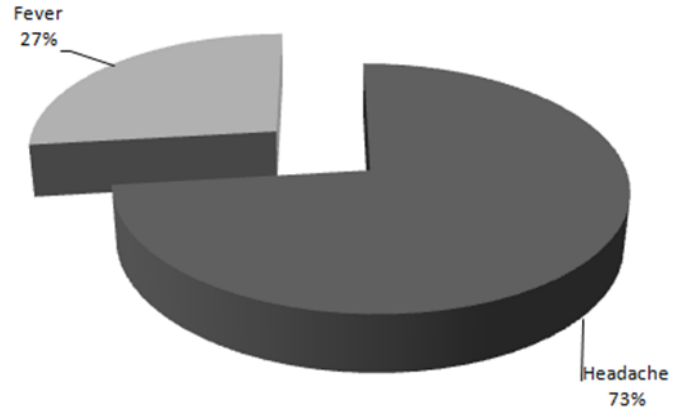

Figure 2 Symptoms for which self-medication has been reported in pregnant women in Brazzaville, 2016.
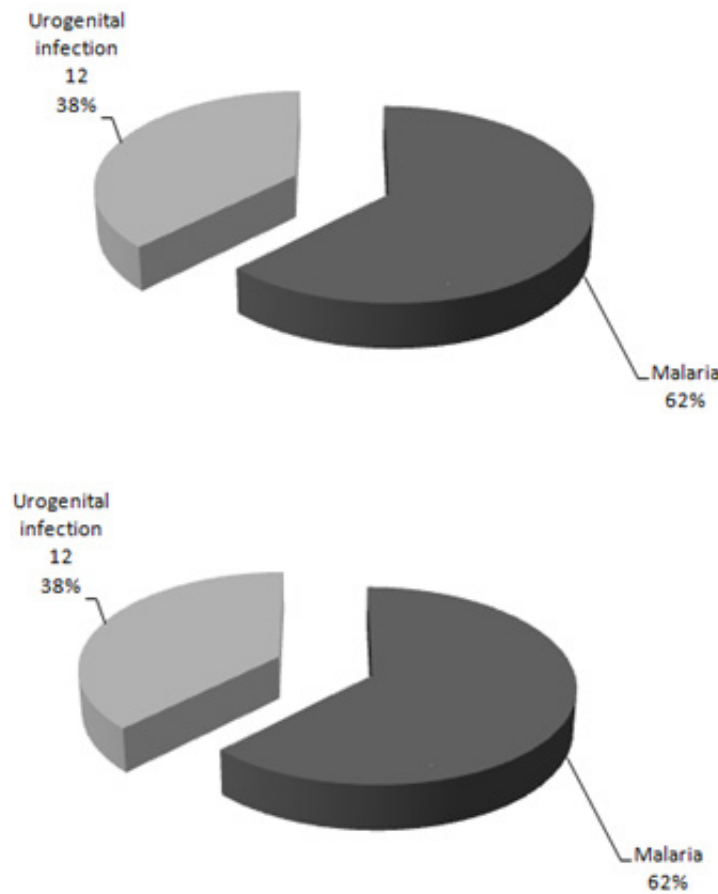

Figure 3 Diseases for which self-medication has been reported in pregnant women in Brazzaville, 2016.

\section{Discussion}

To our knowledge, this is the first study to assess self-medication practice among pregnant women in Congo. We have in this study determined self-medication prevalence in pregnant women, the drugs used and their sources. The study found that the self-medication practice among pregnant women was high $(44,41 \%)$, which is consistent with a previous study showing high satisfaction elsewhere in sub-Saharan Africa. ${ }^{15-18}$ In our study, there were no difference in terms of age, matrimonial status, education, gestation age, history of pregnancies and parity between pregnant women that reported self-medication and those without self-medication. However, the proportion of women with a history of self-medication was higher among women who reported self-medication practice than among women who did not practice. Several study were previously found..$^{7-19}$ Other characteristics have been identified: the gestational age, ${ }^{18}$ occupation, ${ }^{7-18}$ education. $^{7-19}$ But, after adjustment, occupation 
and education were found associated with self-medication. ${ }^{18}$ This corresponds to "diploma effect" reported by Raynaud ${ }^{8}$. This effect can be explained by the fact that educated people do not mind about advice from a health professional and they are confident to know enough to take care of their symptoms by themselves. As previously reported, ${ }^{10}$ paracetamol was most often used as in our study. This can be explained by its high availability in pharmacies and illicit markets and its financial accessibility. ${ }^{14}$ It has no known teratogenic or fetotoxic effects. ${ }^{14-20}$ However, its use at doses above four grams may cause maternal or fetal liver damage..$^{20,21}$ The use of drugs by pregnant women can be harmful to the mother: this is the case for chloramphenicol, taken as self-medication by nine pregnant women to treat without diagnostic arguments what were probably malaria attacks. It may still cause developmental abnormalities or organ maturation defects in the fetus or newborn. ${ }^{19}$ This is the case of drugs contraindicated during fetal life and with mandatory prescription: chloramphenicol, doxicycline, and especially drugs prohibited during pregnancy, non-steroidal anti-inflammatory drugs, diclofenac or ibuprofen used by $24,3 \%$ pregnant women of this study and by $75 \%$ in Lubumbashi in the Democratic Republic of Congo. ${ }^{15}$ This is also the case with cotrimoxazole, and mebendazole (taken because of nausea corresponding to minor ailments of pregnancy often transient). Both of these drugs are very potentially responsible for heart defects, genitourinary malformations and bicycle-palatal clefts in the foetus. ${ }^{15}$

Another major finding of this study is that no woman knew risks associated with drugs they used for self-medications. This reveals lack of quality in prenatal consultations and pharmacies counseling. Drugs subject to a medical prescription were delivered on simple request and without information by the pharmacist.

\section{Conclusion}

The study is limited by the fact that self-medication practice were assessed using self-reports which may be affected by social desirability bias. Nevertheless, the medicine students who conducted women interviews were specifically trained to use nonjudgmental approaches in order to minimize such biases. This study is also limited by the absence of in-depth analysis of factors associated with self-medication practice among pregnant women. More extensive collection of variables would have allowed logistic regression analyses to identify associated factors. ${ }^{18}$ We could not use regression because we compared the two groups (self-medication: Yes/No), we did not observe a significance difference between the two groups.

\section{Acknowledgements}

None.

\section{Conflict of interest}

The author declares there is no conflict of interest.

\section{References}

1. WHO. Relational use of medicines-Geneva: World Health Organization. 2018.

2. Jain S. Concept of self medication: a review. Int J Pharm Biol Arch. 2011;2:19-23.

3. Mikou S, Buire AC, Trenque T. Automédication chez la femme enceinte. Thérapie. 2008;63(6):415-418.
4. Ciarkowski S, Staburg C. Medication Safety in Obstetrics and Gynecology. Clin Obsttr Gynecol. 2010;53(3):428-499.

5. Bello FA, Morhason-Bello IO, Olayemi O, et al. Patterns and predictors of self-medication amongst antenatal clients in Ibadan, Nigeria. Niger Med J. 2011;52(3):153-157.

6. Abasiubong F, Bassey EA, Udobang JA, et al. Self-Medication: potential risks and hazards among pregnant women in Uyo, Nigeria. Pan Afr Med J. 2012;19:13.

7. Ebrahimi H, Atashsokhan G, Amanpour F, et al. Self-medication and its risk factors among women before and during pregnancy. Pan Afr Med J. 2017;7:27-183

8. Raynaud D. Les déterminants du recours à l'automédication. Rev Fr Aff Soc. 2008;(1):81-94.

9. Mouankié JB, Mazonga B, Abena AA. L'automédication chez l'adulte à Brazzaville. Sci Med Afr. 2011;3:459-463.

10. Courrier D, Villier C, Jourdan S. Automédication et grossesse : enquête auprès de 740 femmes dans le réseau périnatal. Alpes-Isère. Rev SageFemme. 2015;14:131-141.

11. Damase-Michel C, Lapeyre-Mestre, Moly C. Consummation de medicaments pendant la grossesse: enquête auprès de 250 femme en consultation dans un centre hospitalier universitaire. J Gynécol Obst Boil Reprod. 2000;29:77-85.

12. Thiele K, Kessler T, Arck P, et al. Acetaminophen and pregnancy: shortand long-term consequences for mother and child. J Reprod Immunol. 2013;97(1):128-139.

13. Toda K. Is acetaminophen safe in pregnancy? Scand J Pain. 2017;17:445446.

14. Jaeschke H. Acetaminophen: Dose-Dependent Drug Hepatotoxicity and Acute Liver Failure in Patients. Dig Dis. 2015;33(4):464 471.

15. Kabamba AT, Shamashanga LK, Mwaba J-JM, et al. Prévalence de l'utilisation des anti-inflammatoires non stéroïdiens chez les femmes enceintes à Lubumbashi (République Démocratique du Congo). Pan Afr Med J. 2014;1:18.

16. Abeje G, Admasie C, Wasie B. Factors associated with self medication practice among pregnant mothers attending antenatal care at governmental health centers in Bahir Dar city administration, Northwest Ethiopia, a cross sectional study. Pan Afr Med J. 2015;20:276.

17. Beyene KG, Beza SW. Self-medication practice and associated factors among pregnant women in Addis Ababa, Ethiopia. Trop Med Health. 2018;46:10.

18. Marwa KJ, Njalika A, Ruganuza D, et al. Self-medication among pregnant women attending antenatal clinic at Makongoro health centre in Mwanza, Tanzania: a challenge to health systems. BMC Pregnancy Childbirth. 2018;18(1):18.

19. Pons E da S, Knauth DR, Vigo Á. Predisposing factors to the practice of self-medication in Brazil: Results from the National Survey on Access, Use and Promotion of Rational Use of Medicines (PNAUM). PloS One. 2017;12(12):e0189098.

20. McLay J, Izzati N, Pallivalapila A, et al. Pregnancy, prescription medicines and the potential risk of herb-drug interactions: a cross-sectional survey. BMC Complement Altern Med. 2017;17(1):543.

21. Elefant E, Bavoux F. Tétratogènese et foetotoxicité médicamenteuse. Rev Prat. 2003;53(57):1920-1925. 